'Fundação Oswaldo Cruz (Fiocruz) - Eusébio (CE), Brasil.

leoemcuba@gmail.com

2 Universidade Federal do Ceará (UFC) - Fortaleza (CE), Brasil.

3 Universidade Regional do Cariri (Urca) - Crato (CE), Brasil.

4 Fundação Oswaldo Cruz (Fiocruz) - Rio de Janeiro (RJ), Brasil.

\section{Estratégia Saúde da Família rural: uma análise a partir da visão dos movimentos populares do Ceará}

\author{
Rural Family Health Strategy: an analysis from the perspective of \\ popular movements in Ceará
}

\author{
Leandro Araujo da Costa', Fernando Ferreira Carneiro', Magda Moura de Almeida², Maria de \\ Fátima Antero Sousa Machado $\mathbf{3}$, Alexandre Pessoa Dias ${ }^{\mathbf{4}}$, Francisco Wagner Pereira Menezes², \\ Vanira Matos Pessoa'
}

DOI: 10.1590/0103-11042019S803

RESUMO A conquista do direito constitucional à saúde não se efetivou em diversos cenários. A partir dessa realidade, em 2011, foi publicada a Política Nacional de Saúde Integral das Populações do Campo, da Floresta e das Águas (PNSIPCFA). Este artigo objetiva analisar as práticas da Estratégia Saúde da Família (ESF) em territórios rurais no Ceará. Trata-se de estudo qualitativo, descritivo, realizado com 5 movimentos populares, sendo 3 entrevistados de cada um deles, totalizando 15 participantes. Utilizaramse entrevista semiestruturada e análise do discurso. Os movimentos apontaram que houve expansão da ESF no campo, com avanços no acesso à saúde, apesar de existirem limitações. O Programa Mais Médicos destacou-se como marco relevante. Os movimentos têm o desafio de se apropriarem da PNSIPCFA, e contribuir, juntamente com ESF, para a ampliação da participação popular em saúde e reconhecimento dos saberes e práticas populares, considerando a determinação social da saúde.

PALAVRAS-CHAVE Estratégia Saúde da Família. Sistema Único de Saúde. Saúde da população rural. Serviços de saúde rural.

\begin{abstract}
The conquest of the constitutional right to health has not been enforced in various scenarios. Considering this reality, in 2011 the National Policy for Integral Health of Countryside, Forest and Water Populations (PNSIPCFA) was published. This article aims to analyze the practices of the Family Health Strategy (FHS) in agricultural territories in Ceará. This is a qualitative, descriptive study, conducted with five popular movements, with 3 respondents from each movement, totaling 15 participants. Semi-structured interview and discourse analysis were used. The movements pointed out that there was an expansion of the FHS in the Countryside, with advances in access to health, despite some restrictions. The More Doctors Program stood out as a relevant milestone. The movements have the challenge of seizing the PNSIPCFA and contribute, along with the FHS, to the expansion of popular participation in health and recognition of popular knowledge and practices, considering the social determination of health.
\end{abstract}

KEYWORDS Family Health Strategy. Unified Health System. Rural health. Services of rural health. 


\section{Introdução}

O Sistema Único de Saúde (SUS) é público e gratuito no Brasil desde a Constituição de 1988. O direito à saúde, todavia, persiste como reivindicação e luta permanente pelas populações rurais, denominadas neste artigo de Populações do Campo (PC). Estas são camponeses, agricultores, populações atingidas por barragens, extrativistas, pescadores, ribeirinhos, quilombolas, entre outros ${ }^{\mathbf{1}}$.

As contradições no campo produzidas pelo capitalismo, tais como a modernização conservadora da agricultura (caracterizado por concentração de terras, expansão de monocultivos, o uso intensivo de equipamentos e o modelo produtivo químico-dependente de agrotóxicos e fertilizantes sintéticos), geraram pobreza e desigualdade, contribuindo para as iniquidades em saúde². Ademais, a falta de políticas públicas no campo intensificou a necessidade organizativa das PC para reivindicar direitos. Nesse contexto, surgiram e se consolidaram os movimentos populares, como: Movimento dos Trabalhadores Rurais Sem Terra (MST), Movimento dos Pequenos Agricultores (MPA), Coordenação Nacional de Quilombolas (Conaq), Confederação dos Trabalhadores e Trabalhadoras na Agricultura (Contag), Comissão Pastoral da Terra (CPT) e outros ${ }^{1}$.

$\mathrm{Na}$ concepção desses movimentos, lutar pela terra é lutar por saúde, o que dialoga com o documento final da VIII Conferência Nacional de Saúde (CNS), em 1986, que afirma a saúde como resultante das condições de alimentação, habitação, educação, renda, meio ambiente, trabalho, transporte, emprego, lazer, liberdade, acesso e posse da terra e acesso a serviços de saúde $^{3}$. Nesse sentido, um conjunto de autores reforça a necessidade de compreender que existem fatores que se relacionam e produzem a determinação social da vida, tendo em sua essência os modos de produção da sociedade, como forma de organizar os aglomerados humanos, interferindo no adoecimento das pessoas e dos territórios ${ }^{4}$.
Desse modo, as ações de Promoção da Saúde (PS) devem visar o empoderamento e autonomia das pessoas e das coletividades para o alcance de melhores condições de vida e saúde 5 . Assim, o conhecimento e a participação popular estão imbricados, sendo estratégicos para a transformação da realidade, explicitada pelo conceito de determinação social da saúde, já que a PS deve voltar-se para além dos muros do setor saúde e incidir sobre as condições de vida das populações. Para tanto, é necessário enfrentar as desigualdades sistemáticas, injustas e evitáveis existentes na sociedade brasileira ${ }^{3,6,7}$.

A Política Nacional de Saúde Integral das Populações do Campo, da Floresta e das Águas (PNSIPCFA) foi resultado de um processo que se iniciou em 2003 (início do Governo Lula), quando o Ministério da Saúde começou a estruturar o Grupo da Terra para responder à necessidade histórica de construção de uma política de saúde para o campo e para conduzir esse processo, de forma a desenvolver uma ação sistêmica para atender às demandas dos movimentos sociais em diálogo com suas áreas estratégicas. O Grupo da Terra contou com a participação de várias áreas técnicas do Ministério relacionadas com o tema, como: Secretaria Executiva, Atenção à Saúde, Vigilância em Saúde, Ciência Tecnologia e Insumos Estratégicos, Gestão do Trabalho e Educação na Saúde, Gestão Participativa; e órgãos vinculados, como Agência Nacional de Vigilância Sanitária (Anvisa), Fundação Nacional de Saúde (Funasa) e Fundação Oswaldo Cruz (Fiocruz).

Em relação à sociedade civil, participavam o Conselho Nacional de Secretários de Saúde (Conass), Conselho Nacional de Secretarias Municipais de Saúde (Conasems) e os movimentos sociais do campo: MST, Contag, CPT e Movimento de Mulheres Camponesas (MMC), com a agregação posterior dos representantes dos seguintes movimentos: Articulação dos Povos Indígenas do Brasil (Apib), Conaq, Federação dos Trabalhadores e Trabalhadoras na Agricultura Familiar (Fetraf), Movimento 
dos Atingidos por Barragem (MAB), Movimento de Luta pela Terra (MLT), Movimento Nacional dos Pescadores (Monape), MPA, Mulheres Trabalhadoras Rurais Movimento das Margaridas (MTRMM), Movimento Interestadual de Mulheres Quebradeiras de Coco Babaçu (MIQCB), Movimento da Mulher Trabalhadora Rural do Nordeste (MMTRNE), Federação dos Pescadores do Estado de Alagoas (Fepeal) e Movimento de Pescadores e Pescadoras Artesanais (MPP) ${ }^{8}$.

A PNSIPCFA visa à redução das iniquidades históricas vividas por esse grupo populacional, notadamente resultantes de condições sociais, como: níveis de escolaridade e renda, condições de moradia, acesso à água e saneamento básico, segurança alimentar e nutricional e participação social; objetivando a melhoria das condições de saúde, o acesso aos serviços, redução dos agravos e riscos consequentes do modelo brasileiro de desenvolvimento no campo 9 .

Dessa forma, a PNSIPCFA buscou preencher uma lacuna histórica na atenção à saúde, reforçando o princípio da equidade no SUS, com foco na identificação das necessidades específicas desses territórios, considerando a determinação social da saúde, os contextos ambientais e culturais do processo saúde/ doença no campo, na floresta e nas águas.

Em 2006, foi publicada a Política Nacional de Atenção Básica (PNAB), revisada em 2012, com objetivo de manter a centralidade da Estratégia Saúde da Família (ESF) e consolidação da Atenção Primária à Saúde (APS), capaz de ampliar a cobertura, fornecendo cuidados integrais com desenvolvimento da PS, configurando a principal porta de entrada do usuário no SUS e eixo de coordenação do cuidado e de ordenação da Rede de Atenção à Saúde (RAS) ${ }^{\mathbf{1 0}}$.

Existem outras políticas públicas de saúde que contribuem para redução das iniquidade no SUS e colaborando para o fortalecimento da PNSIPCFA, como: a descentralização da gestão, o fortalecimento da rede de atenção à saúde, ampliação da cobertura da Atenção Básica (AB), a Rede Cegonha, o Programa
Mais Médicos, a implantação do Centro de Referência em Saúde do Trabalhador Rural (Cerest-Rural), implantação dos Comitês Estaduais de Promoção das Políticas de Equidade dentro dos Conselhos de Saúde, fortalecendo o espaço de gestão participativa e controle social'11.

No entanto, a nova PNAB, reformulada em 2017, estimula relativização da cobertura universal, com definição de padrões distintos de serviços ofertados pela $\mathrm{AB}$, segmentação do acesso ao cuidado com possiblidades de recomposição das equipes, a desvinculação das equipes dos territórios, a desqualificação do trabalho de Agentes Comunitários de Saúde (ACS) e de reorganização do processo de trabalho na $\mathrm{AB}$, permitindo aos gestores municipais uma suposta maior autonomia, enquanto o Ministério da Saúde renuncia à sua responsabilidade de coordenar e induzir as bases da PNAB. Assim, em um país com realidades locorregionais distintas e com um processo de descentralização que necessita de aprimoramentos este modelo torna-se arriscado, na medida em que traz grande risco de desassistência de parte significativa da população e de perda na qualidade dos serviços da $\mathrm{AB}^{10}$.

Assim, considerando que já se passaram oito anos de existência da referida política, indaga-se: como os movimentos populares percebem as práticas da ESF nos territórios do campo no Ceará? Este manuscrito analisa as práticas da ESF em territórios rurais/camponeses no Ceará na visão dos movimentos populares do campo.

\section{Material e métodos}

Estudo de abordagem qualitativa, descritivo-analítico, realizado no Ceará, Nordeste do Brasil. O estado conta com uma população total estimada em 9.705.649 habitantes para 2018 , contando com $80,36 \%$ de cobertura pela ESF $^{12}$. No entanto, não existem dados sobre a população rural estimada para 2018, tendo 
somente dados referentes ao censo do Instituto Brasileiro de Geografia e Estatística - IBGE (2010), sendo 2.104.065 habitantes na zona rural do Cearán' ${ }^{13}$.

A pesquisa foi realizada com cinco movimentos populares do campo do estado do Ceará, que participam do Grupo da Terra no âmbito nacional, sendo eles: CPT, Comissão dos Quilombolas Rurais do Estado do Ceará (Cerquirce), Federação dos Trabalhadores Rurais Agricultores e Agricultoras Familiares no Ceará (Fetraece), MPA e MST. O Grupo da Terra ainda não está constituído no âmbito de estados ou municípios no Brasil.

Foram entrevistadas três pessoas de cada movimento, totalizando 15 entrevistados, obedecendo os seguintes critérios: uma liderança que atua no âmbito estadual, denominada de dirigente ou coordenador estadual; uma liderança que atua no âmbito regional, denominada de militante; e um representante local, residente permanentemente em território/ comunidade organizada pelo movimento, denominado liderança local ou base. As indicações para a entrevista foram feitas pela coordenação de cada movimento.

Utilizou-se para a coleta de dados a entrevista semiestruturada. A pesquisa de campo foi realizada de julho a novembro de 2018. As entrevistas foram gravadas, transcritas e processadas para posterior análise. O roteiro da entrevista abordava situações relacionadas com o modo de assistir as PC por parte da ESF, tendo como perguntas principais relacionadas com os seus respectivos territórios: como é o acesso à saúde? Comente como você vê a atuação e as ações realizadas pela ESF? Que ações da realizadas pela ESF você destacaria? Como as ações de saúde realizadas pela ESF consideram e ou valorizam as práticas populares de saúde? Quem são os profissionais que compõem as equipes da ESF? Quais destes profissionais são residentes/moradores dos territórios? Existem muitas mudanças de profissionais nas equipes de ESF? Tais mudanças implicam no processo de cuidado das pessoas? Para a análise, adotou-se a técnica de Análise do Discurso (AD), que para Orlandi ${ }^{\mathbf{1 4}}$ consiste na extração dos sentidos dos textos, considerando que a linguagem, enquanto trabalho simbólico, não é transparente, mas parte do trabalho social geral, constitutivo do homem e da sua história.

A participação dos convidados foi vinculada à assinatura do Termo de Consentimento Livre Esclarecido (TCLE), sendo-lhes garantidos todos os direitos versados nas Resoluções $n^{\circ} 466$, de dezembro de 2012, e $\mathrm{n}^{\circ} 510$, de abril de 2016, ambas do Conselho Nacional de Saúde. A pesquisa foi aprovada pelo parecer $n^{\circ} 636.427$, de 14/05/2014, do Comitê de Ética em Pesquisa da Faculdade de Saúde da Universidade de Brasília.

Este artigo é resultante da dissertação de mestrado intitulada 'Análise das práticas da estratégia saúde da família na visão dos movimentos populares do campo e das águas do Ceará', defendida em abril de 2019.

\section{Resultados e discussão}

\section{A ESF e a atenção à saúde às Popula- ções do Campo}

Os resultados apontam o modo como a atenção à saúde pela ESF tem ocorrido no cotidiano das PC na visão dos movimentos populares. A ESF consiste no dispositivo assistencial mais próximo das $\mathrm{PC}$, sendo relevante avaliar como está sendo o cuidado a essa população ${ }^{15}$. A realidade do modelo de atenção em saúde realizado pela ESF no campo exige a necessidade de visualizar outras dimensões do cuidar, a partir do contexto social de vulnerabilidade dessa população ${ }^{15}$.

A singularidade relacionada com as PC está assentada no seu modo de vida e produção. Essa relação forte com o território caracteriza de forma definidora a própria identidade dessas populações, como elas o reconhecem, como povos e comunidades que têm seus modos de vida, produção e reprodução social relacionados predominantemente com o campo, com a floresta e com as águas ${ }^{16}$. 
Por isso, a Equipe de Saúde da Família (EqSF), ao adentrar nos territórios camponeses, precisa levar em consideração essa particularidade, visualizar suas necessidades de saúde mediante um processo de territorialização com participação popular, a fim de organizar as ações de saúde, como aponta a liderança local da Fetraece, quando refere que:

tem que ser feito um grande diagnóstico participativo para buscar dentro das comunidades as suas necessidades, e a partir disso, trabalhar o planejamento de curto, médio e longo prazo.

É importante que, no processo de trabalho, exista aproximação da ESF com a comunidade, para que aquela possa entender as particularidades desta:

Uma das coisas que a gente tenta dialogar com essa equipe [equipe de saúde], é que nós temos as nossas particularidades, nós queremos muitas vezes que participem de rodas de conversa dentro da comunidade, dentro do quilombo para que eles conheçam um pouco sobre nós, ainda assim, é um fator ignorado [...]. (Liderança local da Fetraece).

A ESF ainda tem como desafio a inserção comunitária no campo, de modo a se aproximar da comunidade. Fiuza et al. ${ }^{17}$ afirmam que a inserção e a abordagem comunitária são fundamentais para reconhecer o território e requer uma articulação de saberes e experiências, em diálogo com a participação comunitária, respeitando suas identidades, culturas e fortalecendo atores sociais, que realizam cuidados no território. Sendo assim, a ESF que atenda às suas necessidades de saúde em uma perspectiva integral tem que buscar se adaptar aos ritmos da natureza e contar com olhar diferenciado para a diversidade dos modos de produção e geração de vida ou morte nesses territórios.

Nesse caso, é fundamental a territorialização, pois dela decorre a análise da situação de saúde, o planejamento e a implantação de ações estratégicas, que garantam resolubilidade ao sistema. A territorialização permite a obtenção e análise das informações sobre as condições de vida no território, possibilitando conhecer o contexto e compreender sua dinâmica social, econômica e cultural de forma mais ampliada, aproximando-se dos sujeitos dos territórios, principalmente se realizada de forma participativa e inclusiva ${ }^{\mathbf{1 8}, 19}$.

Com a territorialização, é possível conhecer melhor as necessidades de organização do processo de trabalho da ESF no campo, pois quando esta não reconhece as particularidades do território (modo de vida e produção), atua de modo a reproduzir o modelo urbano, como é destacado pela liderança regional da Cerquirce:

É preciso que tenha esse olhar no campo, as políticas sociais sempre foram pensadas no âmbito urbano, mas nós estamos lá no campo, nós existimos, essa especificidade que é ignorada.

Desse modo, a atenção à saúde nesses territórios requer a necessidade de conhecer, valorizar e considerar as suas especificidades:

Respeitar as particularidades de cada um [dos povos], os ciganos têm uma particularidade, os pescadores têm uma particularidade, todos esses povos do campo, das águas e das florestas tem uma particularidade. (Liderança Regional da Cerquirce).

Complementarmente, é preciso avançar para que as EqSF no campo considerem a dimensão territorial e a correlacione ao processo saúde-doença, considerando a determinação e os determinantes sociais da saúde presentes:

Muitas vezes não compreendem a realidade onde as pessoas estão inseridas, a forma de trabalho, a atividade que desenvolve, atividade agrícola, pecuária. Acaba que alguma atividade que desenvolve, agrícola ou pecuária, produz alguma doença, algum agravo da pessoa, muitas vezes a equipe não tem essa aproximação do território e acaba que não identificando isso. (Liderança estadual do MST). 
O modelo de desenvolvimento econômico existente produz impactos no modo de vidas das comunidades e dos trabalhadores, em contextos rurais e urbanos, gerando agravos à saúde decorrentes das modificações ambientais e da forma de organização do trabalho. A ESF necessita avançar na percepção da relação do processo de adoecimento com o modelo de desenvolvimento no campo $\mathbf{1 8 , 2 0 , 2 1}$. Reconhecer a complexidade multidimensional das necessidades em saúde exige um conjunto de ferramentas para aproximações sucessivas da realidade, pois o perfil epidemiológico de uma determinada população é determinado pela estrutura de produção e pela estrutura de consumo (modo de vida) ${ }^{3}$.

Quando a equipe compreende o modo de vida no qual a comunidade está inserida desde o Sertão, a Praia e a Serra, então, cada realidade dessa, é um modo de vida, são culturas diferentes, são trabalhos diferentes, quando a equipe compreende e está inserida nesses territórios, há uma melhor atenção à saúde. (Liderança estadual do MST).

Assim, o modelo de atenção à saúde realizado pela ESF no campo encontra dificuldade em identificar as causas dos adoecimentos, dificultando a realização das ações de prevenção e de PS. Há um despreparo das EqSF para reconhecer os saberes populares e incorporá-los no planejamento do cuidado em saúde, como também a baixa realização de atividades educativas, que podem ser ou não catalizadoras de mudanças na promoção de saúde.

Considerando a ESF na AB o principal espaço para o desenvolvimento de ações de educação em saúde, este pode ser considerado um ambiente favorável ao desenvolvimento da educação popular em saúde22,23. Mesmo sendo um ambiente favorável para ações fundamentadas na integralidade da atenção e no princípio dialógico do conhecimento entre saberes diferentes, essas potencialidades não garantem a substituição do modelo biomédico (tradicional, vertical e orientado para as doenças). Portanto, é preciso uma nova postura dos profissionais, maior participação da comunidade e maior permeabilidade dos serviços às necessidades e demandas da população ${ }^{23}$.

Fundamentalmente, praticar uma ecologia de saberes (diálogo entre os diversos saberes, combinação e articulação de conhecimentos diferentes - populares e científicos - com vista a fortalecer as ações coletivas acordadas) seria uma possibilidade de avançar na $\mathrm{ESF}^{\mathbf{2 0 , 2 4}}$.

Não tenho percebido grandes reclamações das populações da zona rural em relação ao serviço de saúde, mas percebo a ausência de campanhas de prevenção sobre diversas doenças, a falta de valorização dos saberes populares, a falta de diálogo com as populações do campo sobre cuidados e doenças específicas de sua realidade, um total desconhecimento do cenário que envolve o uso de agrotóxicos e a consequente falta de interesse e de ações na prevenção e combate às doenças causadas pelos agrotóxicos. (Liderança estadual da CPT).

É importante visualizar que a entrevistada percebe e destaca os agrotóxicos como um problema vivido, e ainda, um desconhecimento acerca das consequências para a saúde humana, sem mencionar o impacto ambiental. Isso permite indagar sobre a formação das EqSF para abordar temas relacionados com o modelo de desenvolvimento adotado no campo, que tem estimulado, cada vez mais o uso intensivo de agrotóxicos 21,25,26.

$\mathrm{A}$ atenção à saúde realizada pela ESF no campo ainda encontra dificuldade no que se refere a PS e prevenção de doenças, centrando suas ações no atendimento individual curativo, reproduzindo o modelo biologicista, como é referido pela liderança regional do MST, ao afirmar que:

em todas as comunidades que conheço até agora, tanto numa como em outra, a equipe vai mais para o cuidado mesmo, vai mais para atender, diagnosticar e passar a receita, encaminhar mesmo para exames. 
Essa forma de realizar atenção à saúde pela ESF, pautada no atendimento individual e focada na doença, também é referenciada por uma liderança do MPA, ao apontar que, os atendimentos

ficam muito centrados nas consultas, às vezes, eles realizam algum evento dentro do postinho, eu não vejo realizando nas comunidades, fica muito centralizado no postinho.

A atenção à saúde praticada pela ESF no campo ainda está distante dos princípios da ESF, que busca garantir atenção integral, com foco nas famílias. As ações voltadas para participação comunitária e PS ainda são fragilizadas nos territórios das PC, como é relatado abaixo.

[...] eu vivo numa região fortemente impactada pelos agrotóxicos das empresas do agronegócio e, por vezes, também utilizados pelos agricultores. Não há nenhuma orientação sobre as consequências dos agrotóxicos para a saúde humana por parte dos gestores e profissionais da saúde. (Liderança estadual da Fetraece).

Por outro lado, os ACS conseguem representar diferencial por meio de suas ações nas EqSF no campo, como relata liderança local da Cerquirce, quando diz que "quem realmente vem para a comunidade são as agentes de saúde, os profissionais como médico, dentista, eles ficam mais na sua base mesmo, no posto".

O ACS teve, desde a sua criação uma atuação mais próxima do território, já que seu trabalho é centrado na visita domiciliar. Em cenários do campo, em que há comunidades espaçadas geograficamente, ele é um profissional fundamental nessa aproximação em territórios de difícil acesso pela EqSF.

Segundo Bornstein e Stotz ${ }^{24}$, a função mediadora dos ACS pode ser de grande importância na mudança do modelo assistencial, mas cabe perguntar se a ESF contém os elementos que permitem o desenvolvimento do potencial transformador dos agentes, portanto, há que se investir na formação deles.
No Ceará, esses profissionais só realizaram a qualificação básica, nunca tendo concluído o curso técnico de ACS.

Um destaque que daria aqui, é a presença de lideranças, agentes da CPT, que são Agentes Comunitários de Saúde, elas tão no lugar do vivido, estão no lugar da identidade socialmente construída, esse agente de saúde advindo da experiência do sindicato, da CPT, da comissão pastoral da terra, tem um outro jeito de fazer que vai de encontro ao papel que é o agente de saúde. (Liderança regional da CPT).

O ACS aproxima-se da identidade do território, não se restringindo às atividades demandadas pelo serviço de saúde, o que faz com que a população o veja como membro da equipe de saúde, mas também, como membro da comunidade, convivendo com a realidade e com as práticas de saúde existentes ${ }^{27}$. Assim, há um duplo papel desenvolvido pelo ACS, pois acaba sendo, ao mesmo tempo, agente e sujeito, e, portanto, tem um potencial importante para as ações de PS e de transformação do território $\mathbf{2 8}$.

Outra observação mencionada é que há uma desvalorização dos saberes das PC, visto como o não reconhecimento das práticas populares de saúde pela ESF, como afirma a Liderança regional da Cerquirce:

[...] Nós usarmos remédios das plantas medicinais dentro do território é uma resistência [...] A grande maioria dos médicos, dos profissionais de saúde, eles ignoram completamente esse nosso saber.

Para Silva ${ }^{29}$, as práticas populares de saúde são saberes que integram a vida das PC, essas práticas estão inseridas no cotidiano das comunidades camponesas, notadamente nos assentamentos, acampamentos, comunidades tradicionais, nos quilombos e reservas extrativistas. Essas práticas populares de cuidado em saúde precisam ser reconhecidas e compreendidas pela EqSF, para que a equipe possa construir alianças terapêuticas e planos de 
cuidado integral. Reconhecer e dialogar com as práticas populares de saúde existentes pode colaborar para a qualidade de vida da PC, contribuindo para a transformação do cuidado em saúde, que, mediante a educação popular, podem gerar ações que direcionam para a PS.

[...] a equipe não procura saber se tem esse tipo de cuidado [práticas populares de saúde], que se sabe, e que tão ali, todos os dias, que se cuidam e cuidam do outro. Não procuram saber se no território tem pessoas, que possam fazer isso, que possam promover a saúde, [...] não procuram identificar espaços que cuidam. (Liderança regional do MST).

Rückert, Cunha e Modena ${ }^{30}$ apontam que as práticas populares de saúde são concebidas por meio da apreensão e leitura de mundo pelos povos, de suas heranças culturais, de suas vivências e suas condições de vida, que possibilitam a autonomia, de modo a serem sujeitos ativos na promoção de sua saúde e autocuidado. Dessa forma, a ESF, em muitos momentos, não atua de modo a efetivar a Política Nacional de Práticas Integrativas e Complementares (PNPIC), consequentemente, não identificando ou reconhecendo as práticas populares de saúde nos seus territórios.

Embora compreendamos que existe hoje a política que contempla essas práticas integrativas, infelizmente não existe ainda o conhecimento de todas as equipes dessas práticas e muitas vezes não são reconhecidas, aí fica só no remédio e só isso não dá conta. (Liderança estadual do MST).

Para Pinheiro e Bittar ${ }^{31}$, o diálogo é um processo árduo e que exige abertura e capacidade de escuta, em que o profissional tenha a capacidade de lidar com a aflição de ter seu saber contrariado, e de saber visualizar os saberes populares, a partir da visão dos sujeitos, que vivem nos territórios, ainda que divergindo do seu olhar. Assim, cada população, seja do campo, da floresta e das águas, tem o seu modo de produção e reprodução social, cultural, econômico que precisam ser compreendidos, a fim de buscar estratégias às suas demandas e necessidades de saúde, pois essas populações guardam um saber ancestral muitas vezes ancorados em um profundo conhecimento da relação entre a natureza, a biodiversidade de seu território e sua saúde ${ }^{\mathbf{1 6}}$.

Outro aspecto relevante na edificação dos serviços e ações de saúde no campo é a dificuldade de permanência dos profissionais de saúde nos territórios. Os entrevistados referem que há rotatividade de profissionais na ESF, com destaque para o médico, fragilizando o vínculo e a longitudinalidade do cuidado:

O médico é o que mais troca [rotatividade], isso é muito ruim para gente. Primeiro, que para você falar sobre você, você precisa também conhecer um pouco do médico, ter um pouco de vínculo, essa rotatividade quebra, esmaga esses vínculos, que eu penso muitas vezes, não pode criar vínculo, tem sim, que criar vínculo, o profissional médico e o paciente, pode haver vínculos e não vai atrapalhar e não vai tirar dele o profissionalismo. (Liderança regional da Cerquirce).

Essa rotatividade de profissionais afeta toda a dinâmica assistencial preconizada pela ESF, como podemos constatar na percepção abaixo:

[...] quando acontece essa rotatividade por mais que seja um bom desempenho para o desenvolvimento da atividade deles, quebram um pouco, porque quando acontece a rotatividade, eu acredito que quando se troca de profissional, o paciente em si, o indivíduo em si, deixa de ser bem mais assistido na minha visão. (Liderança local do MST).

Um fator agravante da situação é a desigualdade distributiva dos médicos, profissional de maior dificuldade de fixação, reflexo da atração destes por cidades de maior porte populacional, localizadas em regiões economicamente mais desenvolvidas, que oferecem maiores oportunidades educacionais e profissionais. A atração e a fixação de médicos são 
um problema complexo, que envolve motivações intrínsecas e extrínsecas que influenciam a escolha do local de atuação do profissional ${ }^{32}$.

Permanece, dessa forma, como um desafio o avanço do acesso ao atendimento médico para a PC. Como afirma Stralen et al. . $^{32}$, não existe uma fórmula única para promover a atração e fixação de médicos em áreas remotas e desassistidas e, portanto, a atração e fixação de profissionais deve ser um exercício constante entre os planejadores de recursos humanos em saúde ${ }^{32}$.

Em muitos municípios, identifica-se a redução da carga horária de trabalho para os médicos, associada à alta rotatividade das equipes, comprometendo a prestação dos cuidados e a qualidade da assistência na APS ${ }^{33}$. Outro fator que influencia a rotatividade de profissionais está relacionado com a mudança dos gestores do poder executivo nos municípios, como referido abaixo:

Geralmente, há rotatividade no período pós-gestão, pós-mudança de eleição, há uma rotatividade da equipe, daqueles que não são concursados, passa aí modificam geralmente um médico, enfermeira, muitas vezes, o dentista, e aí, a equipe perde o ritmo que vinha anteriormente, conhecer a realidade, os casos de cada indivíduo, até pegar esse ritmo novamente há uma perda. (Liderança estadual do MST).

Existem motivações tanto objetivas como subjetivas na rotatividade de médicos e enfermeiros na APS. Tal motivação decorre de situações como o vínculo precário na contratação e dificuldades de relacionamento político entre profissional e gestor. Portanto, é importante a promoção da desprecarização dos vínculos trabalhistas, fundamentalmente mediante concurso público, com um plano de cargos e salários que estimule os profissionais à qualificação para o trabalho e permanência na ESF. O modelo de gestão participativa favorece a permanência dos profissionais e pode resultar em satisfação e comprometimento com a proposta da $\mathrm{ESF}^{34}$.
A partir desse cenário, adotou-se o Programa Mais Médicos para o Brasil (PMMB), em 2013, que possibilitou o avanço no acesso e permanência do profissional médico nesses territórios:

Nos últimos anos, o Mais Médicos possibilitou o tempo maior do médico na comunidade, e que $o$ atendimento se voltasse um pouco mais à realidade da família e da atividade que a família desenvolve, isso foi positivo e ajudou todo mundo aqui no nosso território. (Liderança estadual do MST).

O PMMB apresentou-se como estratégia de melhoria da cobertura da ESF e fortalecimento da APS, tendo como iniciativas levar profissionais médicos para regiões onde havia essa escassez; investimentos na construção, reforma e ampliação das unidades básicas de saúde e instituindo qualificação da formação médica ${ }^{35}$. Ele possibilitou a fixação de médicos em regiões vulneráveis e com iniquidades sociais, sendo muitas regiões de vivência das $\mathrm{PC}^{35}$; elevou o número de médicos na $\mathrm{ESF}$, com melhor assistência, oferecendo alívio ao problema da escassez de médico de forma emergencial ${ }^{36,37}$, ampliou o acesso à saúde e possibilitou novas práticas de cuidado, fortaleceu a integração das equipes, apoiando a organização dos serviços, contribuindo para o fortalecimento da $\mathrm{APS}^{38}$.

O PMMB trouxe mudanças nas ações da ESF com a vinda de profissionais estrangeiros, principalmente cubanos, que realizam uma prática médica mais voltada para a promoção e prevenção, distanciando-se do modelo hospitalocêntrico, com atenção mais integral e valorizando os aspectos culturais da população $0^{39,40}$.

[...] quando chegou o Programa Mais Médicos, a grande maioria dos profissionais, eles eram médicos formados em Cuba. Eles foram formados dentro dessa lógica de cuidar bem das pessoas, desse cuidado de uma saúde mais humanizada e utilizando práticas integrativas. (Liderança estadual da Fetraece). 
Os movimentos populares apontaram sugestões para a organização do processo de trabalho das EqSF do campo, conforme o relato a seguir:

Fazer um levantamento das situações específicas que impactam sobre a saúde dos povos do campo, da floresta e das águas. Depois, uma discussão ampla, envolvendo as comunidades, os profissionais da saúde, os gestores, sobre as políticas públicas de saúde e sua contextualização. Em seguida, adequar os serviços de saúde às necessidades reais destes povos. E, por fim, criar um espaço de permanente de planejamento, monitoramento e avaliação das políticas públicas de saúde para o campo. A partir de então, garantir o orçamento necessário para a execução das políticas públicas. (Liderança Nacional da CPT).

Outra sugestão apontada para melhorar as ações de trabalho da ESF no campo foi a realização de processo formativo permanente para os profissionais que atuam nas EqSF:

[...] qualificar os profissionais na área de saúde, às vezes, não recebe nenhum tipo de qualificação, formação continuada e integrar a questão do sistema público de saúde com a realidade local com o ponto de vista social, das práticas complementares, eu avalio que seja essas três coisas ajudaria muito a melhorar a situação das populações do campo, da floresta e das águas. (Liderança Nacional da Contag).

A percepção dos movimentos populares do campo no Ceará acerca das práticas da ESF precisa ser compreendida no contexto estadual. O estado foi pioneiro na implantação dos ACS (1986) e da ESF (1991), com histórico de incentivo e apoio à APS. Todavia, a ampliação do acesso aos serviços na lógica da PS persiste como um grande desafio.

As entidades do Campo do Ceará também guardam suas especificidades organizativas e políticas, mas, quando se trata da forma como percebem a ESF nas áreas rurais, foi encontrada relevante convergência nos discursos. A realidade de como se vive a falta de acesso à saúde nesses territórios na visão dos entrevistados, por exemplo, é muito semelhante como já indicaram outros autores ${ }^{\mathbf{8} 41}$.

Destaca-se, fundamentalmente, a necessidade de as EqSF conhecerem o território, as características da população, o modo de vida, a cultura; e ter a sensibilidade de perceber como os impactos das transformações decorrentes do modelo de desenvolvimento no campo incidem no processo saúde-doença das populações desses territórios, como uma dimensão para o planejamento de práticas de saúde coerentes com a realidade camponesa.

\section{Considerações finais}

As práticas de saúde na ESF no campo no Ceará ainda não atendem às necessidades e aos problemas de saúde do território, primordialmente por desconsiderar: o modo de vida, o modelo de desenvolvimento, a participação comunitária, os saberes populares e as práticas populares de saúde já existentes. Esses aspectos corroboram para a preservação e reprodução de modelo biomédico e distanciamento do modelo orientado pela PS.

Apesar disso, houve expansão da ESF, garantindo acesso e assistência à saúde nas comunidades camponesas, mesmo com limitações do modelo assistencial. Há dificuldades de fixação dos profissionais nesses territórios, principalmente do médico. A rotatividade dos profissionais também associa-se à precarização do trabalho das EqSF. A rotatividade dificulta a constituição de vínculo, inserção territorial, longitudinalidade do cuidado, o que compromete o cuidado integral. Destacou-se o PMMB na melhoria desses atributos na ESF no campo. O único profissional com notável inserção comunitária citado foi o ACS, que está presente nos territórios, dialogando com o modo de vida das PC.

A visão dos movimentos populares do campo, na perspectiva da garantia do direito à saúde, considerando a implementação da PNSICFA, reforça que a atuação da ESF no 
campo deve: realizar territorialização participativa para reconhecimento dos modos de vida, do modelo de desenvolvimento, bem como das fortalezas e das ameaças à saúde da população em seus territórios; incorporar ações das práticas populares de cuidado existentes no território; valorizar os cuidadores(as), potencializando o empoderamento popular mediante a educação popular em saúde; adotar estratégias de contínua formação dos profissionais de saúde, a fim de facilitar a compreensão da diversidade social, étnica, política e cultural desses territórios; e, também, maior abordagem na formação profissional das políticas de equidade no SUS, em especial, a PNSIPCFA, a Política Nacional de Saúde Integral da População Negra (PNSIPN), a PNPIC e a Política Nacional de Educação Popular em Saúde (PNEPS), pois são fundamentais para realização do processo de trabalho nesses territórios; reforçar a relevância do PMMB para provimento de médicos para campo; e fortalecer necessariamente a ESF como modelo assistencial primordial no campo, pois, mesmo com os limites, garante o acesso ao serviço de saúde; investir no ACS como protagonista para atuação comunitária, com foco na família; e fomentar mecanismos de participação popular, que possibilitem a escuta qualificada da comunidade.

Ademais, os movimentos populares do campo precisam se apropriar da PNSIPCFA, a fim de reivindicar sua implementação, como meio para efetivação do direito à saúde, e fortalecer a participação popular nos seus territórios. A ESF necessita ampliar sua visão de saúde e cuidado, considerando a construção histórica dos movimentos populares do campo na luta contra todas as formas de opressão, promovendo em conjunto a construção de uma sociedade mais justa e igualitária.

\section{Colaboradores}

Costa LA (0000-0002-8475-5288)*, Carneiro FF (0000-0002-6625-9715)*, Almeida MM (0000-0002-4806-2345)*, Machado MFAS (0000-0002-2541-8441)*, Dias AP (0000-0002-5594-7221)*, Menezes FWP (0000-0001-5877-6504)* e Pessoa VM (00000003-3676-9607)* contribuíram para a concepção, planejamento, análise e interpretação dos dados; elaboração do rascunho e revisão crítica do conteúdo; e aprovação da versão final do manuscrito. 


\section{Referências}

1. Carneiro FF, Pessoa VM, Teixeira ACA. Campo, floresta e águas: práticas e saberes em saúde. Brasília, DF: UnB; 2017.

2. Delgado GC, Cardoso Junior JC, organizadores. A universalização de direitos sociais no Brasil: a previdência rural nos anos 90. 2. ed. Brasília, DF: Ipea; 2002.

3. Pettres AA, Ros MA. A Determinação Social da Saúde e a Promoção da Saúde. Arq. Catarin Med. 2018; 47(3):183-196.

4. Breilh J. Las tres 'S' de la determinación de la vida: 10 tesis hacia una visión crítica de la determinación social de la vida y la salud. In: Nogueira RP. Determinação social da saúde e reforma sanitária. Rio de Janeiro: Cebes; 2010. p. 112-123.

5. Czeresnia D, Freitas CM. Promoção da saúde: conceitos, reflexões, tendências. 2. ed. Rio de Janeiro: Fiocruz; 2009.

6. Porto MFS, Cunha MB, Pivetta F, et al. Comunidades ampliadas de pesquisa ação como dispositivos para uma promoção emancipatória da saúde: bases conceituais e metodológicas. Ciênc. Saúde Colet. 2016; 21(6): 1747-1756.

7. Garbois JA, Sodré F, Dalbello-Araujo M. Da noção de determinação social à de determinantes sociais da saúde. Saúde debate. 2017; 41(112):63-76.

8. Carneiro FF. A saúde no campo: das políticas oficiais à experiência do MST e de famílias de "bóias frias" em Unaí, Minas Gerais, 2005 [tese]. Belo Horizonte: Universidade Federal de Minas Gerais; 2007.

9. Brasil. Ministério da Saúde. Portaria no 2.311, de 23 de outubro de 2014. Altera a Portaria no 2.866/GM/ MS, de 2 de dezembro de 2011, que institui, no âmbito do Sistema Único de Saúde (SUS), a Política Nacional de Saúde Integral das Populações do Campo e da Floresta (PNSIPCF). Diário Oficial da União. 27 Jul 2013. [acesso em 2020 jan 10]. Disponível em: http://bvsms.saude.gov.br/bvs/saudelegis/gm/2014/ prt2311_23_10_2014.html.

10. Morosini MVGC, Fonseca AF. Revisão da Política Nacional de Atenção Básica numa hora dessas? Cad. Saúde Pública. 2018; 33(1):1-4.

11. Silva FCCM. Promoção da equidade no SUS: saúde integral das populações do campo, da floresta e das águas. Fortaleza: Fundação Demócrito Rocha; 2014.

12. Instituto Brasileiro de Geografia e Estatística. Pesquisa Nacional por Amostra de Domicílios 2015 [internet]. Brasília, DF: IBGE; 2015. [acesso em $2018 \mathrm{dez}$ 10]. Disponível em: http://www.biblioteca.ibge.gov. br/visualizacao/livros/liv98887.pdf.

13. Instituto Brasileiro de Geografia e Estatística. Censo Demográfico 2010 -Características Gerais da População. Resultados da Amostra [internet]. Brasília, DF: IBGE; 2010. [acesso em 2018 dez 10]. Disponível em: http://www.ibge.gov.br/home/estatistica/populacao/cnso2000/default_populacao.shtm.

14. Orlandi EP. Análise do discurso: princípios e procedimentos. Campinas: Pontes; 2000.

15. Targa LV. Área rural. In: Gusso G, Lopes JMC. Tratado de Medicina de Família e Comunidade. Porto Alegre: Artmed; 2019. p. 431-442.

16. Silva FCM. Política Nacional de Saúde Integral das Populações do Campo, da Floresta e das Águas e o Ambiente. In: Brasil. Ministério da Saúde. Secretaria de Gestão Estratégica e Participativa. Departamento de Apoio a Gestão Participativa, Organizador. Saúde e Ambiente para as Populações do Campo da Floresta e das Águas. Brasília, DF; 2015.

17. Fiuza TM, Ribeiro MTAM, Esteche FF. Abordagem comunitária: inserção comunitária. In: Gusso G, Lopes JMC, Dias LC. Tratado de Medicina de Família e Comunidade: Princípios, formação e prática. Porto Alegre: Artmed; 2019. p. 159-166. 
18. Pessoa VM, Rigotto RM, Carneiro F. Sentidos e métodos de territorialização na atenção primária à saúde. Ciênc. Saúde Colet. 2013; 18(8):2253-62.

19. Borges C, Taveira VR. Territorialização. In: Gusso G, Lopes JMC, Dias LC, organizadores. Tratado de Medicina de Família e Comunidade: Princípios, formação e prática. Porto Alegre: Artmed; 2019. p. 241-247.

20. Pessoa VM. Ecologia de saberes na tessitura de um pensamento em saúde no sertão: do conhecimento regulação às práticas emancipatórias na estratégia saúde da família [tese]. Fortaleza: Universidade Federal do Ceará; 2015.

21. Carneiro FF, Rigotto RM, Augusto LGS. Dossiê ABRASCO: um alerta sobre os impactos dos agrotóxicos na saúde. São Paulo: Expressão Popular; 2015.

22. Albuquerque PC, Stotz EN. A educação popular na atenção básica à saúde no município: em busca da integralidade. Interface. 2004; 8(15): 258-74.

23. Bornstein VJ, Stotz EN. O Trabalho dos agentes comunitários de saúde: entre a mediação convencedora e a transformadora. Trab educ saúde. 2008; 6(3):457480.

24. Santos BS. Prefácio. In: Carneiro FF, Pessoa VM, Teixeira ACA, organizadores. Campo, floresta e águas: práticas e saberes em saúde. Brasília, DF: UnB; 2017.

25. Rigotto RM, Carneiro FF, Marinho AMCP. O verde da economia no campo: desafios à pesquisa e às políticas públicas para a promoção da saúde no avanço da modernização agrícola. Ciênc. Saúde Colet. 2012; 17(6):1533-1542.

26. Pessoa VM, Rigotto RM. Agronegócio: geração de desigualdades sociais, impactos no modo de vida e novas necessidades de saúde nos trabalhadores rurais. Rev bras Saúde ocup. 2012; 37(125):65-77.

27. Fraga OS. Agente comunitário de saúde: elo entre a comunidade e a equipe da esf? [Monografia]. Belo Horizonte: Universidade Federal de Minas Gerais; 2011.
28. Losco LN, Gemma SFB. Sujeitos da saúde, agentes do território: o agente comunitário de saúde na Atenção Básica ao imigrante. Interface (Botucatu). 2019; 23(18):1-13.

29. Silva FCCM, Gonçalves JWS, Santorum JA. Saúde integral das populações do campo, da floresta e das águas. Fortaleza: Fundação Demócrito Rocha; 2014.

30. Rückert B, Cunha DM, Modena CM. Saberes e práticas de cuidado em saúde da população do campo: revisão integrativa da literatura. Rev Interface comun saúde educ. 2018; 22(66):903-14.

31. Pinheiro BC, Bittar CML. Práticas de educação popular em saúde na atenção primária: uma revisão integrativa. Cinergis. 2016; 18(1):77-82.

32. Stralen ACSV, Massote AW, Carvalho CL. Percepção de médicos sobre fatores de atração e fixação em áreas remotas e desassistidas: rotas da escassez. Physis. 2017; 27(1):12-27.

33. Miranda GMD, Mendes ACG, Silva ALA. A Ampliação das Equipes de Saúde da Família e o Programa Mais Médicos nos Municípios Brasileiros. Trab Educ Saúde. 2017; 15(1):131-145.

34. Medeiros CRG. A rotatividade de enfermeiros e médicos: um impasse na implementação da Estratégia de Saúde da Família. Ciênc. Saúde Colet. 2010; 15(1):15211531.

35. Silva FCCM. Contribuições do Programa Mais Médicos e da Estratégia de Saúde da Família no acesso à saúde das populações do campo, da floresta e das águas. In: Carneiro FF, Pessoa VM, Teixeira ACA. Campo, floresta e águas: práticas e saberes em saúde. Brasília, DF: Universidade de Brasília; 2017. p. 132-43.

36. Girardi SB, Stralen ACS, Cella JN. Impacto do Programa Mais Médicos na redução da escassez de médicos em Atenção Primária à Saúde. Ciênc. Saúde Colet. 2016; 21(9):675-84.

37. Lima MC, Teixeira ACA, Barros E. O fazer rural. In: Gusso G, Lopes JMC, organizadores. Tratado de Me- 
dicina de Família e Comunidade. Porto Alegre: Artmed; 2012. p. 77-84.

38. Kemper ES, Mendonça AVM, Sousa MF. Programa Mais Médicos: panorama da produção científica. Ciênc. Saúde Colet. 2016; 21(9):2785-96.

39. Rios DRS, Teixeira C. Mapeamento da produção científica sobre o Programa Mais Médicos. Saúde Soc. 2018; 27(3):794-808.
40. Martins ACP, Sant'anna PA, Rocha JFD. Programa mais médicos: uma revisão integrativa. Rev Bras Promoç Saúde. 2017; 30(4):1-14.

41. Silva FCCM. Saúde das populações do campo, da floresta e das águas: luta, conquista e direito [dissertação]. Rio de Janeiro: Escola Nacional de Saúde Pública Sergio Arouca, Fundação Oswaldo Cruz; 2016.

\footnotetext{
Recebido em 02/06/2019

Aprovado em 21/10/2019

Conflito de interesses: inexistente

Suporte financeiro: não houve
} 